HETEROTOPIAS: superfícies da formação do ator

HETEROTOPIES: surfaces of the formation of the actor

\author{
Gilberto Dos Santos Martins \\ gilsantins@gmail.com \\ Instituto Federal de Educação, Ciência e Tecnologia do Maranhão
}

\begin{abstract}
Resumo:
Tendo em vista que cada encenador exige uma determinada técnica para cada proposta estética, os atores envolvidos nesse processo devem acessar campos outros na complementação de suas técnicas. Assim, este artigo tem por objetivo realizar uma breve discussão acerca das espacialidades que compõem a formação do ator. Tomamos como base teórica o conceito de Heterotopia, formulado pelo filósofo francês Michel Foucault (1926-1984), onde o mesmo vai apresentar a temática espacial como o grande eixo temático do século XX. Lançamos mão do conceito e propomos a observância da diversidade espacial que os atores na contemporaneidade dispõem para realizar a sua formação e/ou continuá-la.
\end{abstract}

Palavras- chave: Formação, ator, espacialidades.

\begin{abstract}
:
Given that each director requires a certain technique for each aesthetic proposal, the actors involved in this process must access other fields in the complementation of their techniques. Thus, this article aims to make a brief discussion about the spatialities that make the formation of the actor. We take as theoretical basis the concept of Heterotopy, formulated by the French philosopher Michel Foucault (1926-1984), where it will present the spatial theme as the great thematic of the twentieth century. We take advantage of the concept and propose the observance of the spatial diversity that contemporary actors have to carry out their formation and / or to continue it.
\end{abstract}

Keywords: Training, actor, spatialities.

O tema da formação do ator há muito vem ocupando as rodas de debates e escritas de vários pesquisadores e artistas. Este assunto, que por mais debatido e que, a priori, possa parecer saturado, ainda nos move e conduz a discuti-lo, quer na esfera de sua metodologia, quer na esfera do aprendizado.

Quando permeamos por essas trilhas logo nos vem de súbito ideias que estão plantadas no senso-comum da formação, que é a de acúmulo de ideias ou depósito dessas de um sujeito a outro. Aqui, para além da transmissão nos disporemos a discutir os variados espaços que possibilitam o engendramento de conhecimentos para que o sujeito/ator possa realizar sua prática com afinco e independência. 
Para isso, partiremos do conceito de Heterotopia, proposto pelo filósofo francês Michel Foucault (1926-1984) para pensar quais multiplicidades de espaços o ator tem para sua formação inicial e manter-se em formação. Não nos deteremos em esmiuçar o conceito e sim tomá-lo como trampolim para refletir a questão da espacialidade na formação do ator. Desse modo nos aparecem algumas questões que demarcarão nosso discurso neste texto: Quais espaços o interessado em formar-se enquanto ator pode recorrer para realizar um estudo? Apenas escolas e conservatórios se configuram enquanto espaços que levam uma troca de conhecimento teatral? Nesse sentido, como um espaço fechado, quadrado em suas estruturas e métodos como uma escola de teatro ou conservatório, pode proporcionar uma troca de experiência que enverede o sedento por conhecimento a sua autonomia criativa e intelectual?

\section{Espaços variados}

Ao se referir ao que mais foi dada atenção nas questões temáticas do século XIX, Foucault, em conferência denominada Dits et écrits, Des espaces autres no ano de 1984, entende que esse século estava voltado para as temáticas da história, ou seja, as crises, as ascendências e decadências de sociedades, eram os conteúdos primeiros nos debates. Junto a isso, esse século seria a preparação para a realização de todos os sonhos, de todos os ideais e planos, à sua concretização no século seguinte, no entanto sabemos que o século $X X$ foi bastante subversivo, no sentido de que as maiores guerras e conflitos sociais emergiram nesse período.

Muito embora esse século tenha sido, a princípio, o da decepção, Foucault o aponta como o século do espaço, acoplando a simultaneidade, a justaposição, como fatores determinantes e próprios dessa época. Parafraseando o filósofo, o século XIX, configurou-se como um instante em que o mundo se experimentou bem menos; o século $X X$ seria o momento em que as redes se religam aos pontos entrecruzando suas tramas. As subjetividades, os conflitos de pontos de vistas criaram um sistema complexo de relações que não seria mais possível partir apenas pelo campo da objetividade. Aqui se estabelece um campo de batalha ideológico entre os que agitam a bandeira do tempo e os que agitam a da espacialidade (FOUCAULT, 2009, p.411). 
Entretanto, essa espacialidade proposta aqui como discussão e refletida por Foucault não está isenta de uma historicidade, não sendo assim, uma exclusividade do século em pauta; esse espaço com a temática temporal se entrecruzaram inevitavelmente no percurso histórico.

\begin{abstract}
Pode-se dizer, para retraçar muito grosseiramente essa história do espaço, que ele era, na Idade Média, um conjunto hierarquizado e lugares: lugares sagrados e lugares profanos, lugares protegidos e lugares, pelo contrário, abertos e sem defesa, lugares urbanos e lugares rurais (onde acontece a vida real dos homens); para a teoria cosmológica, havia lugares supracelestes opostos ao lugar celeste; e o lugar celeste por sua vez, se opunha ao lugar terrestre; havia os lugares onde as coisas se encontravam colocadas porque elas tinham sido violentamente deslocadas, e depois os lugares, pelo contrário, onde as coisas encontravam sua localização e seu repouso naturais. Toda essa hierarquia, essa oposição, esse entrecruzamento de lugares era o que se poderia chamar bem grosseiramente de espaço medieval: espaço de localização. (FOUCAULT, 2009, p. 412)
\end{abstract}

Podemos perceber que na era medieval o ponto de localização, de posicionamento imóvel, permeava as relações tanto espaciais, literalmente, mas também as sociais, pois a localização da posição social, muito raramente, ou quase nunca era levada a mover-se; topograficamente, pensar nas linhas existentes além do mar era quase inimaginável, ou quando pensadas, impingidas pela mítica de então.

Segundo Foucault (2009, p. 412), a ideia de "espaço de localização" iniciou-se com Galileu na era medieval. O cientista nos apontou para uma perspectiva até então não cogitada, onde afirma a não centralidade da Terra no Universo, e que esta gira entorno do Sol. Nesse momento, reflete Foucault, Galileu dá um grande passo na condução do olhar, do que antes estava voltado à realidade espacial micro europeia, à outras extensões. Imaginar que o ponto de localização ao qual se pertence, não mais se configura como o centro é lançar mão de extensões, deslocamentos, lugares e posicionamentos que geram outros espaços quando tomados como uma realidade, física e concreta.

De volta ao século XX, o posicionar-se está intimamente ligado aos posicionamentos dos pares e como esses pares, ou vizinhos dentro de uma rede se posicionam, sugere um ponto de vista, ou onde se está fincada uma grade que a todo instante se movimenta no sentido do reestabelecimento do lugar. As relações em grades estabelecem interesses ou os definem. O teórico revela que em meio a esse século tumultuado ao qual estamos dedicando nossa atenção, a preocupação demográfica talvez não seja a questão chave mas como nos posicionamos, nos localizamos e em 
quais circunstância em benefício de um ou de outro resultado; "estamos em uma época em que o espaço se oferece a nós sob a forma de relações de posicionamentos.

Embora muitas investidas tenham sido realizadas no tocante à espacialidade contemporânea, ainda existem relações que são intocáveis, oposições que em seu corpus são mantidos em redomas cristalizadas, sacralizadas. Este último termo resgatamos da escrita do teórico que estamos nos fundamentando na escrita deste texto.

Foucault nos provoca na observância do espaço de fora, não o de dentro ao qual Gaston Bachelard realizou uma extensa reflexão, mas esse espaço que nos conduz ao deslocamento, no qual se assenta o devir da vida humana, um espaço, assim, heterogêneo.

Pensando na heterogeneidade e preenchimento espacial, o filósofo nos apresenta um conceito ao qual nos servirá de mola propulsora para a reflexão dos posicionamentos e localizações da formação do ator na contemporaneidade. Heterotopia seria então:

Lugares reais, lugares efetivos, lugares que são delineados na própria instituição da sociedade, e que são espécies de contraposicionamentos, espécies de utopias efetivamente realizadas nas quais os posicionamentos reais, todos os outros posicionamentos reais que se podem encontrar no interior da cultura estão ao mesmo tempo representados, contestados e investidos, espécies de lugares que estão fora de lugares, embora eles sejam efetivamente localizáveis. Esses lugares, por serem absolutamente diferentes de todos os posicionamentos que eles refletem e dos quais falam, eu os chamarei, em oposição às utopias, de heterotopias; e acredito que entre as utopias e estes posicionamentos absolutamente outros, as heterotopias, haveria, sem dúvida, uma espécie de experiência mista, mediana, que seria o espelho." (FOUCAULT, 2009, p. 415)

O ator na contemporaneidade vem buscando conhecimentos em diversos espaços, uma formação que podemos dizer não unilateral, mas plurilateral. Essa é uma realidade cada dia mais comum. A partir desse olhar, de "outros lugares", definição grosseira de heterotopia, podemos começar a problematizar os espaços reservados à formação do ator. Como questionamos nos início deste artigo, seriam as escolas ou conservatórios, os únicos espaços que abrigam formas de aprendizagem de um ator? Quais espaços heterotópicos podemos vislumbrar para conseguirmos esse propósito? 


\section{Heterotopias na formação}

Quando pensamos num trajeto que se inicia no século XX e se desenrola até os nossos dias, podemos constatar as variações e perspectivas que se tem dado ao ator. As várias propostas de trabalho e de acepções que se tem dado ao teatro, têm também modificado o "conceito" de ator, se é que podemos atribuir esse termo. Há quem os queira melhorar, há quem os queira suprimir, há quem os ver como corpo, ou palavra, ou ações ou apenas imagem. Esses procederes tem requerido uma técnica específica, um controle corporal único, um domínio da palavra e da espacialidade que em outrora era negligenciado, ou até mesmo desconhecido.

Em termos de formação, a cada dia vem crescendo o número de espaços dedicados à introjeção de técnicas para polir o ator para determinados trabalhos, ou até mesmo num sentido do acúmulo de técnicas e métodos prontos para serem aplicados quando necessário. Apesar de muitas discussões sobre a necessidade de conhecimentos técnicos e habilidades ao ator, vale aqui pensarmos que espaços são esses, e como se tem configurado a formação do ator nos nossos dias.

Conceber uma formação universal em um mesmo espaço é inconcebível, pelo menos até a elaboração deste texto. $O$ indivíduo quando se insere no âmbito teatral e busca uma formação para ator, normalmente, inicia dentro de uma escola, ou grupo teatral, mas logo percebe que esses espaços não são suficientes para agregar o conhecimento que lhe é exigido para determinados espetáculos.

Portanto, quando se tem uma formação onde a palavra é o centro das atenções e a senhora do palco, e por ventura se está num elenco onde o trabalho e elasticidade corporal é essencial para a estética da obra, inevitavelmente, deve-se recorrer a lugares ou pessoas que estão direcionadas para esse elemento. Vale ressaltar que, a dicotomia corpo e palavra, há muito vem sendo desconstruída e esse binômio, hoje, está restrito um único termo, corpo; não nos aprofundaremos nesta discussão aqui, pois não é nosso foco.

Beatrice Picon-Vallin (2008) ao realizar uma abordagem às origens da encenação, afirma que as primeiras preocupações com a "preparação" do ator, acompanham o surgimento da figura do encenador no final do século XIX e início do XX. Podemos recuar um pouco e trazer o encena- 
dor francês André Antoine (1858-1943) para esse discurso, visto que o mesmo apresentou preocupações sobre o ator e seu desempenho em cena no século XIX.

Para a autora o advento do surgimento de estúdio, de escola, de atelier ou de laboratório, se originou para atender as necessidades mais imediatas das produções cênicas de então. Cada encenador propõe uma estética diferenciada e propósitos filosóficos distintos. Com essa variação de campos solicitados para cada proposta, os atores que estão envolvidos devem atendê-las com maior afinco possível.

Essa necessidade de transmissão de saberes também está ligada a um fator histórico; as inúmeras guerras civis e a tão comentada revolução de 1917 fez com que grandes nomes do teatro, sobretudo russo, se expatriassem, formando, assim, cursos em diferentes localidades da Europa (PICON-VALLIN, 2008, p 166).

$\mathrm{Na}$ atualidade, com o discurso cênico bastante desenvolvido, as linguagens artísticas estão cada dia mais integradas, formando uma única célula estética; a variedade de técnicas exigidas para elaborar um espetáculo é latente. Esses atores que estão imersos nesses processos, tentam adquirir um conjunto de técnicas para atender certo tipo de espetáculo, no entanto, essas não necessariamente atenderão a outra obra que por ventura o grupo ou companhia de teatro venha a realizar.

A partir dessas proposições, podemos elencar localidades, ou espaços diferenciados, onde os atores comumente buscam conhecimentos para agregar a sua formação: Escolas, Conservatórios, oficinas, grupos, workshops, residências, etc.

O sociólogo Jean Duvignaud (1972, p. 197), ratifica a importância de uma formação para se chegar a determinados papeis e que para "assegurar a respectiva existência imaginária" do personagem faz-se mister passar por um período de preparação. Na França, no final do século XIX e início do XX, inúmeros atores contraíram uma dívida educacional com as escolas de teatro e/ou conservatórios para garantirem o "domínio da máscara." Outros a obtiveram através de suas práticas nos teatros, apresentando todas as noites e inspirando-se nos grandes atores e suas descobertas e chaves para alcançar o ponto central da interpretação.

Segundo Duvignaud (1972, p. 198) "é no clima da escola (ou companhia) que o adolescente aprende o teatro, descobre as suas possibilidades, isto é, o que se chama na gíria de seu "emprego"'”. O sociólogo com suas considerações nos mostra aqui dois espaços onde o ator pode adquirir 
técnicas para seu ofício: a escola e a companhia. Em relação a primeiras muitas ressalvas foram feitas pelo encenador André Antoine.

O encenador francês, certamente por não conseguir seus propósitos estéticos com um veIho estilo de interpretar, faz uma dura crítica ao jeito pomposo adquirido nos conservatórios pelos atores de então. Estes, que receberam indicações para "acentuar corretamente, gritar de acordo com as regras, fazer todas as ligações entre as palavras sob pena de parecer vulgar e familiar", quase nunca agem com naturalidade e sensibilidade.

Aprenderam a procurar efeitos de pormenor, sem interesse e sem significado para o conjunto, a solicitar a qualquer preço a aprovação do público por processos e truques de profissão. Só têm ao seu serviço, para traduzir o indivíduo que representam dois únicos instrumentos, a voz e a cara; o resto do corpo não participa na ação. Usam luvas, vem sempre em traje de gala e, não possuindo mais as farpelas majestosas ou elegantes de antigamente, trazem uma flor na botoeira e anéis. (BORIE, ROUGEMONT E SCHERER, 1996, p. 369)

Antoine provoca ao atribuir aos movimentos clássicos do teatro a deformação dos atores, que por uma razão ou outra ignoram as "complicações, as variedades, os matizes, a vida do diálogo moderno, a destreza das frases, as suas entoações indiretas, subentendidos e seus silêncios eloquentes" (BORIE, ROUGEMONT E SCHERER, 1996, p. 369), ou seja, são atores formados num paradigma inexorável onde a maleabilidade física e imaginativa são impossíveis. Para o encenador o conservatório é composto por um ensino gelado, aplicado, indiscriminadamente, a todo e qualquer tipo de jovem, tornando-o uma vítima de um procedimento unilateral de investigação no teatro e que as escolas mascaram e homogeneízam as inclinações desses jovens negligenciando em detrimento de seus currículos.

Por outro lado, Antoine comunga com a precisão da formação dentro do espaço da companhia, ou grupos teatrais, onde o conhecimento é obtido na prática na presença do público. Esta atitude é bastante comum no Brasil, nos chamados teatros de grupo.

No que concerne à pluralidade espacial de formação contemporânea podemos pensar as Residências artísticas como um espaço destinado a prática formativa do ator.

Parafraseando Vasconcelos (2012, p.03) atualmente as Residências Artísticas têm se firmado como um frutífero espaço de troca de saberem artísticos. E tem cumprido um importante papel na formação de atores, artistas plásticos, performers, músicos, bailarinos, etc. Espaço dedica- 
do ao compartilhamento de informações em espaços e tempos outros que não fazem parte da rotina desse artista.

Existem algumas possibilidades de pensamento acerca da residência artística; em uma delas se destaca a transitoriedade e globalização do nosso posicionamento em relação aos espaços que nos relacionamos e a outra entenderíamos como um espaço de formação e experimentação artística e cultural (MORAES, 2009 apud VASCONCELOS, 2012, p. 03). As duas, portanto, ligadas às heterotopias que configuram a formação do ator, do ser humano; a multiplicidade de espaços que dão substrato para consolidação dos conhecimentos adquiridos fragmentados no dia a dia.

Neste sentido, dois conceitos estão diretamente relacionados à ideia de residência artística: tempo e espaço. O primeiro deles, o tempo, é importante, pois, ao se colocar outra dimensão de tempo à disposição do artista, retirando-o de seu ritmo habitual a partir do deslocamento, proporciona-se a ele outro olhar sobre seu trabalho ator. No segundo caso, o espaço torna-se único a partir de novas perspectivas de ação. (VASCONCELOS, 2012, p.03)

Essa relação tempo e espaço é fundamental na concepção de Residência Artística, visto que, nesse caso atores, devem se deslocar de um contexto de criação que está habituado para outro e, consequentemente, retirados de um tempo que haviam adquirido de produção para outro mais compacto e intenso de dedicação a sua arte. Assim, "a residência passa a ser um espaço singular onde o artista pode pensar sobre sua própria arte, discuti-la, vivenciá-la e recriá-la em suas múltiplas possibilidades no contato com o novo, diferente e diverso" (VASCONCELOS, 2009, 03).

O termo Formação do Ator se apresenta bastante genérico quando começamos a discutir a figura do ator. Sabemos que existem técnicas que vão compondo esse sistema de formação. Essa "educação" para o ator está fixada em camadas espaciais diversificadas. Essas camadas dividem-se em reais e irreais. Os planos reais são aqueles que se apoiam na materialidade espacial, e onde se inferioriza ou superioriza os saberes adquiridos. Nesses lugares existem indivíduos que transferem um saber que, na maior parte dos casos, se cristalizam e inclinam o ator para determinada vertente ou particularidade do teatro.

No que concerne aos irreais, esses indivíduos buscam no campo da não materialidade e do autodidatismo as diversidades espaciais que vez ou outro põe os pés para dá consistência a seu saber; geralmente livre de didatismos alheios, busca no acaso e pelo seu aprofundamento de leituras e vivências suas escolhas e perspectivas para lidar com o ofício. 
Diante dessas camadas formativas, há também espaços organizados que durante suas produções levam o ator para vários lugares estéticos e consequentemente apresentam outras formas de lidar com o corpo, com o "estar em cena". Grupos de atores ao se unirem dentro de uma proposta de pesquisa realizam buscam que inconscientemente geram um saber no ator e que são levados adiante para outros aprendizes.

Bem, o juízo aqui não é frutífero; deixar que se amalgamem essas heterotopias do ator é acreditar na versatilidade criativa, física e intelectual do sujeito eleito a dá experiência as seres, sem os quais não teriam vida nos espaços imaginativos dos indivíduos. É perceptível no teatro contemporâneo posicionamentos e não mais localização de preceitos e estéticas formativas que cristalizam e enrijecem o ator impedindo-o de estar fluído em cena e no mundo.

\section{Referências}

BORIE, M., ROUGEMONT, M. de, SCHERER, J.. Estética teatral: textos de Platão a Brecht. Trad. Helena Barbas. Lisboa: Fundação Calouste Gulbenkian, 1996.

DUVIGNAUD, Jean. Sociologia do Comediante. Trad. Hesíodo Facó. Rio de Janeiro: Ed. Zahar, 1972.

FOUCAULT, Michel. Estética: literatura, pintura, música e cinema. Rio de Janeiro. Ed. Forence universitária: 2001. Volume 03; p. 411-422.

MORAES, Marcos José Santos. Tese de doutorado. Residência artística: ambientes de formação, criação e difusão. Apresentada ao Programa de Pós-graduação da Universidade de São Paulo, Faculdade de Arquitetura e Urbanismo, São Paulo, 2009.

PICON-VALLIN, Béatrice. A encenação: história e técnica de uma arte em movimento. Revista Ouvirouver. 04. Uberlândia, Universidade Federal de Uberlândia. Departamento de Música e Artes Cênicas. 2008. (p.158-186).

VASCONCELOS, Ana. Residências Artísticas como Políticas Públicas no âmbito da FUNARTE. (Artigo). Rio de Janeiro. Políticas Culturais Casa Rui Barbosa. 2012.

Artigo submetido em 06/03/2017, e aceito em 05/04/2018. 